\title{
IdeAs
}

Idées d'Amériques

17 | 2021

Villes et culture dans les Amériques

\section{Irreparable: Resistencia y políticas de respetabilidad en Colombia}

\section{Anthony Dest}

\section{OpenEdition}

1 Journals

Edición electrónica

URL: https://journals.openedition.org/ideas/11181

DOI: 10.4000/ideas.11181

ISSN: 1950-5701

Editor

Institut des Amériques

Referencia electrónica

Anthony Dest, «Irreparable: Resistencia y políticas de respetabilidad en Colombia», IdeAs [En línea], 17 | 2021, Publicado el 01 marzo 2021, consultado el 07 junio 2021. URL: http://journals.openedition.org/ ideas/11181 ; DOI: https://doi.org/10.4000/ideas.11181

Este documento fue generado automáticamente el 7 junio 2021

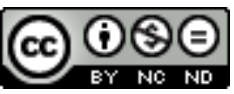

IdeAs - Idées d'Amériques est mis à disposition selon les termes de la licence Creative Commons Attribution - Pas d'Utilisation Commerciale - Pas de Modification 4.0 International. 


\title{
Irreparable: Resistencia y políticas de respetabilidad en Colombia
}

\author{
Anthony Dest
}

Aprecio las conversaciones sobre este artículo con Daniel Campo, Sofía Garzón, Óscar Pedraza, Luciane Rocha, Gimena Sánchez-Garzoli, Shreyas Sreenath, Elizabeth Velásquez Estrada, y Coletta Youngers. También agradezco los comentarios de Laura Cahier y Laetitia Braconnier Moreno. Destaco la generosidad de Daniel Campo y Sofía Garzón por su ayuda con la traducción del artículo al castellano.

\section{En toda época ha de intentarse arrancar la tradición al respectivo conformismo que está a punto de subyugarla.}

\section{Rumores y Hummers}

1 Estábamos en una sala de conferencias a unas cuadras de la Casa Blanca. Una funcionaria de la Embajada de Colombia destacó a propósito de la víctima que defendió a narcotraficantes y que andaba por Cali en una Hummer" ${ }^{1}$. La persona a quién se refería - Hernán Darío Escobar, abogado colombiano - fue abaleada desde un auto en mayo de 2011. La funcionaria de la Embajada sugería que Hernán Darío Escobar no era un noble líder social, ni un defensor de los oprimidos sino que recibió su merecido. Mientras Escobar se moría en el hospital, ella y otros funcionarios del gobierno colombiano intentaron evitar una crisis de relaciones publicas rotando la narconarrativa entre sus contactos en el Congreso de los Estados Unidos. En ese mismo momento se encontraban en el proceso de años de tratar de impulsar la firma del Tratado de Libre Comercio (TLC) entre Colombia y los Estados Unidos, y otro asesinato de un líder social amenazaba con socavar sus planes.

2 En la organización de derechos humanos donde yo trabajaba, intentamos apresuradamente esclarecer los hechos del asesinato y ubicarlo dentro del contexto de violencia sistemática en contra de sindicalistas y activistas de movimientos sociales en Colombia. Los rumores que salían de la Embajada de Colombia tenían el objetivo de 
contradecir nuestro comunicado de prensa inicial sobre el intento de asesinarlo. Como activistas diligentes, ya estábamos acostumbrados a los intentos del gobierno de menospreciar el asesinato de líderes sociales manchando sus nombres. Al describir el asesinato como un ataque en contra de los corteros de caña que Escobar representaba sin cobrar, argumentamos que este hecho de violencia sí era significativo.

Esta experiencia me ha preocupado por casi una década. Por supuesto, la actitud de la funcionaria en relación con el asesinato de un ser humano era de mal gusto, pero no era motivo de sorpresa. A pesar de que la Embajada de Colombia suplicaba por paciencia y respeto al debido proceso cuando nosotros denunciamos asesinatos y amenazas de muerte, siempre parecían "saber" cuándo un bienhechor tenía un lado malo. Por ejemplo, el exministro de Defensa Luis Carlos Villegas indicó esto en 2017 cuando argumentó que la "inmensa mayoría" de los asesinatos de líderes sociales fueron "fruto de un tema de linderos, de un tema de faldas, de un tema de reivindicación, de un tema de pelea por rentas ilícitas" (El Espectador, 2017). Estos tipos de comentarios difamatorios representan un esfuerzo por desmentir la posibilidad de que los activistas fueran objeto de violencia por su trabajo político o que la violencia pudiera haber sido asociada con la continuidad del conflicto armado. Esta disposición hostil del Estado hacia los activistas es garantía de impunidad en la mayoría de los casos de violencia.

4 Mi problema, sin embargo, se relacionaba con la manera en que yo hacía parte de la lógica del estado de enmarcar la violencia. En vez de rechazar el hecho de la violencia y su uso como un medio de legitimar el poder estatal, sostuve las políticas de respetabilidad implícitas en las formas liberales del activismo de derechos humanos. Las feministas negras han criticado los limites de las políticas de respetabilidad por mucho tiempo. En vez de buscar el reconocimiento o el acceso al establecimiento a través de personificar el ciudadano modelo por medio de las políticas de respetabilidad, Cohen sugiere que "una política de desviación" (politics of deviance) puede aumentar "el potencial transformador [...] para mejorar radicalmente las vidas y posibilidades de las personas más vulnerables en comunidades Negras" (Cohen C., 2004, p. 30). Para que la muerte de Escobar les importara a los políticos en los Estados Unidos y en Colombia, su reputación tenía que ser intachable. Adherirse a las políticas de la respetabilidad garantiza que algunas vidas y temas valgan la pena, mientras otras vidas y temas se quedan al margen, y de esta manera, se permitió que el estado controle la conversación

\section{Impidiendo la resistencia}

$5 \quad$ Este tipo de desprestigio está relacionado con el poder de las políticas de respetabilidad para impedir la resistencia. Posicionan al "criminal" como un sujeto irreparable, y las organizaciones que luchan en solidaridad con los supuestos "criminales" son culpables por asociarse con ellos. El conflicto armado colombiano ha servido como pretexto para estigmatizar las reputaciones de activistas. Con solo insinuar que una persona estaba vinculada con un grupo guerrillero, esa persona terminaba ligada a una lista cada vez más larga de etiquetas condenatorias: "comunista", "terrorista", "narcoterrorista", "castro-chavista", etc. Incluso funcionarios con largas historias de participación en la política electoral no son inmunes a esta práctica, y las luchas que privilegian formas individualistas de liderazgos son aún más susceptibles a esta forma de estigmatización.

Los efectos de estas dinámicas son especialmente difíciles para personas con perfiles más bajos. Para muchos activistas, las consecuencias por ser acusado de tener vínculos 
con un grupo armado o con traficantes de drogas pueden ser fatales. El creciente número de bajas registradas en las páginas web de organizaciones de derechos humanos demuestra el escalamiento de la violencia. Las acusaciones también pueden resultar en encarcelamientos. A lo largo de los últimos diez años, tres de mis colegas del Proceso de Comunidades Negras (PCN) pasaron años en la cárcel por acusaciones falsas sobre su apoyo a grupos guerrilleros. Es difícil exagerar la cantidad de energía dedicada a limpiar sus nombres con la esperanza de organizar una amplia campaña de solidaridad para apoyarlos a ellos, a sus familias y sus comunidades. Sin embargo, para muchas personas potencialmente solidarias, la carga de enfrentar el estigma de su posible culpabilidad fue demasiado grande y eligieron apoyar otras causas menos comprometedoras.

7 En ese sentido, los defensores de derechos humanos pueden convertirse en "agentes activos en la guerra por el silenciamiento" (Taussig M., 1989, p. 20). En este contexto de guerra, la exigencia quimérica por casos claros de víctimas perfectamente inocentes bloquea la posibilidad de asumir las realidades complicadas que la gente enfrenta. En su análisis de cómo las víctimas se neutralizan como sujetos políticos en el imaginario liberal del "posconflicto", Pedraza y Álvarez argumentan:

Aunque en la práctica la manera en que las víctimas definen su experiencia no es reducible a categorías homogéneas y estáticas, en general la experiencia política y legal de lo que se denomina "víctima" ha sido reducida a una serie de elementos morales que despojan el carácter político de su historia y la subsumen en una narrativa del trauma, el sufrimiento y el dolor.

(Pedraza Ó. \& Álvarez C., 2016, p. 175)

8 Esta moralidad es especialmente clara en zonas del país como el norte del Cauca que son fuertemente afectadas por la violencia y el tráfico de drogas. Por ejemplo, después del asesinato de una persona indígena en un pueblo cocalero en septiembre 2020, un activista asociado con el movimiento indígena aseguró en su denuncia pública que la víctima "no tiene rol de liderazgo". Este pronunciamiento implicaba que el asesinato podría haber tenido más importancia si la víctima fuera un líder indígena. También, aparentemente, aseguraba que el movimiento podría evitar los peligros de reclamar un posible criminal como si fuera uno de los suyos. Como abolicionista, Gilmore aborda este "problema de inocencia" de la siguiente manera: "Insistir en la inocencia es rendirse políticamente porque 'la inocencia' evita un problema que la abolición debe de enfrentar: cómo disminuir y remediar el daño en vez de buscar mejores formas de castigo" (Gilmore R., 2017, p. 236). Así que, estos tipos de pronunciamientos y las narrativas de víctimas puras contribuyen al discurso dominante de violencia justa/ injusta con todos sus arraigos moralistas y punitivistas. En las palabras de Taussig, este rendimiento político "es más que la producción de silencio. Es silenciar, lo cual es algo muy distinto" (Taussig M., 1989, p. 14).

\section{Más allá de las políticas de respetabilidad}

Las políticas de respetabilidad silencian. El asesinato de Escobar pasó al ultimo trasfondo de nuestro trabajo en la organización de derechos humanos. No dejamos de condenar la violencia, pero nos concentramos en otros casos que pudieran darnos una ventaja política más clara. La decisión acerca de cuales casos íbamos a asumir implicaba revisar bastantes ejemplos para encontrar algo ganable e innegable, lo cual también implicaba meterse en las varias maneras de interpelación que determinan la respetabilidad y la 
criminalidad. Mientras tanto, los casos con los detalles dudosos que se aproximaban a lo "criminal" frecuentemente quedaron en la impunidad. Aunque esta estrategia hace posible un grado de reacción entre las instituciones, tiene como efecto que muchos más casos se queden por fuera del juego. Rechazar las políticas de respetabilidad puede prevenir el preciado acceso a instituciones que constituye la base del activismo de derechos humanos convencional. Sin embargo, rechazar la política de respetabilidad también contiene la posibilidad de interrumpir un sistema político fundamentado en el uso de la violencia en contra de los sujetos que construye como desechables.

\section{BIBLIOGRAFÍA}

Benjamin, Walter, “Theses on a Philosophy of History”, in Hannah Arendt (ed.), Illuminations: Essays and Reflections, New York, NY: Schocken Books, 2007, p. 253-264.

Cohen, Cathy, "Deviance as Resistance: A New Research Agenda for the Study of Black Politics", Du Bois Review, vol. 1, 2004, p. 27-45.

El Espectador, “Asesinatos de líderes son por 'líos de faldas': ministro de Defensa”, El Espectador, 17 December 2017, https://www.elespectador.com/noticias/politica/asesinatos-de-lideres-sonpor-lios-de-faldas-ministro-de-defensa/, Accessed on 13 October 2020.

Gilmore, Ruth Wilson, “Abolition Geography and the Problem of Innocence”, in Gaye Theresa Johnson and Alex Lubin (eds.), Futures of Black Radicalism, London, Verso, 2017, p. 225-240.

Pedraza, Óscar and Camilo Álvarez, "Maquinarias transicionales y neutralización política de las víctimas en Colombia", in Neyla Graciela Pardo Abril and Juan Ruiz Celis, Víctimas, memoria y justiciar: aproximaciones latinoamericanas al caso colombiano, Bogotá, Colombia, Universidad Nacional de Colombia, 2016.

Taussig, Mick, “Terror as Usual: Walter Benjamin's Theory of History as a State of Siege”, Social Text, No. 23, 1989, p. 3-20.

\section{NOTAS}

1. Este artículo se basa en mi experiencia de trabajo en una organización no gubernamental (ONG) de derechos humanos en Washington, DC, entre 2010 y 2012. Desde entonces, he seguido colaborando estrechamente con activistas de derechos humanos en diversos temas como académico y como parte de mis compromisos politicos. 


\section{AUTOR}

\section{ANTHONY DEST}

Anthony Dest es Profesor Asistente de Antropología en Lehman College. Su tesis doctoral, Después de la Guerra: Violencia y Resistencia en Colombia (Universidad de Texas, Austin), fue reconocida como la Mejor Disertación de 2019 por la Asociación de Estudios sobre Paz y Justicia. Su trabajo ha sido apoyado por el National Science Foundation, el Social Science Research Council y la Fundación Interamericana. anthony.dest@lehman.cuny.edu 